\title{
Anomalous hydrocracking of triglycerides over CoMo-catalyst-influence of reaction intermediates
}

\author{
M ANAND, M G SIBI, D VERMA and A K SINHA* \\ Indian Institute of Petroleum-CSIR, Dehradun 248 005, India \\ e-mail: asinha@iip.res.in
}

MS received 15 October 2013; revised 31 December 2013; accepted 2 January 2014

\begin{abstract}
Reaction intermediates have been identified and followed to understand anomalous cracking of jathropha oil triglycerides in the presence of sulphided Co- $\mathrm{Mo} / \mathrm{Al}_{2} \mathrm{O}_{3}$ catalyst. Undesirable $\mathrm{C}-\mathrm{C}$ coupling reactions are favoured at temperatures between $320^{\circ}$ and $340^{\circ} \mathrm{C}$, giving waxy oligomerization products, whereas at temperatures above $340^{\circ} \mathrm{C}$, direct hydrocracking of triglycerides to lighter and middle distillates were favoured. To minimize undesirable waxy oligomerization products, higher pressures ( $>80$ bar) and higher $\mathrm{H}_{2} /$ feed ratios (>1500) were necessary. Aldol condensation and ketonization reactions between the reaction intermediates are counter-productive as they result in waxy long chain oxygenated products which tend to accumulate on the catalyst surface, choke the reactor and cause rapid catalyst deactivation. Reaction conditions have to be optimized to minimize condensation reaction during this process.
\end{abstract}

Keywords. Coupling reactions; hydroconversion; waxy products; reaction intermediates; triglycerides; biofuels.

\section{Introduction}

Currently, industry and transport sector are inherently based on costly and unsustainable crude oil sources. There is an increasingly recognized need to slow down the use of fossil fuels, since they are depleting and cause global warming and pollution. There is need to develop alternative energy fuels which must be economically competitive, technically feasible and environmentally more acceptable. One possible alternative is the fuels produced from renewable resources such as vegetable oils. Hydroprocessing of vegetable oil produces high quality renewable diesel which can replace diesel in vehicles without any major modifications of the engines, while aviation fuel produced from vegetable oils can either directly or as a blend with fossil fuel, be used for aviation purposes. ${ }^{1-4}$ Since biofuels do not add carbon dioxide to the atmosphere, they are carbon neutral fuel, and are also environment-friendly because they do not release nitrogen and sulphur compounds.

The most common way to produce biofuel is to transesterify triglycerides of vegetable oil with alcohol to make biodiesel, which contains oxygenated species. A better way would be to hydroprocess triglycerides to produce petroleum such as fuels. Chemically, biodiesel

*For correspondence consists of fatty acid alkyl esters, and the type of alkyl chain determines the quality of the product. Use of neat biodiesel requires some modification in the existing vehicle engines, and additionally it gives poor performance in cold weather. Alternatively, fuel produced from hydroprocessing is hydrocarbon-like and requires no modification in the existing engines and also has a higher cetane number (85-110) than conventional diesel fuel (51-60). This process involves hydrodeoxygenation, decarbonylation, decarboxylation, hydrocracking and isomerization or a combination of two or more for conversion of fatty acids in triglycerides into normal and/or iso-alkanes. ${ }^{5-7}$ The first step in plantoil hydroprocessing for the production of hydrocarbon fuels is saturation of double bonds in the triglyceride molecule (TG), then the saturated triglyceride molecule (TG) is hydrogenated and cracked to liberate an acid $\left(\mathrm{R}_{x} \mathrm{COOH}\right) /$ aldehyde $\left(\mathrm{R}_{x} \mathrm{CHO}\right) /$ alcohol $\left(\mathrm{R}_{x} \mathrm{OH}\right)$ and a propane molecule. $\mathrm{R}_{x}$ may be either a $\mathrm{C} 15$ or $\mathrm{C} 17$ compound depending on chain length of the triglyceride molecule. The oxygen molecule may be removed by either hydrodeoxygenation $\left(-\mathrm{H}_{2} \mathrm{O}\right)$; or hydrodecarboxylation $\left(-\mathrm{CO}_{2}\right)$; or by hydrodecarbonylation reaction $(-\mathrm{CO}){ }^{8-12}$

The choice of catalyst is important due to its role in controlling the type of product, yield, selectivity, etc., of components present in the biofuel through hydroconversion process. Main properties of the catalyst are surface area, pore shape and size, acidity, metal 
dispersion, etc. Literature reports that various types of porous sulphided catalysts have been used for production of biofuels from vegetable oils. Acidic supports such as silica-alumina ${ }^{10,11}$ (for catalysts such as sulphided Co-Mo, Ni-Mo, Ni-W) and crystalline acidic supports such as hierarchical mesoporous zeolites have been successfully employed to produce cracked hydrocarbons. ${ }^{12-14}$ Yield of cracked products increased with increasing acidity of the catalysts. As the reactions are highly exothermic, catalyst selection based on its stability are important. Increase in acidity in reaction media due to formation of fatty acids at different processing conditions leads to formation of undesired waxy reaction intermediates via $\mathrm{C}-\mathrm{C}$ coupling reactions, which further impacts catalyst life. ${ }^{13,15}$

For a sustainable commercial future for biomassderived fuels by hydroprocessing, detailed studies on better understanding of the underlying mechanisms and reaction pathways are necessary. Kráret et al. ${ }^{16}$ demonstrated that a $\mathrm{CoMo} / \mathrm{Al}_{2} \mathrm{O}_{3}$ catalyst was suitable for deoxygenation of sunflower oil. Kubicka et al. ${ }^{15}$ demonstrated that Co-Mo supported over mesoporous alumina are active for deoxygenation of rapeseed oil. They had observed and discussed formation of oligomeric oxygenates (selectivity as high as 50\%) below $280^{\circ}$ C. Significant amounts of esters such as stearyl stearate were identified as the dominant ester at lower space velocity $\left(1.5 \mathrm{~h}^{-1}\right)$ and lower reaction temperature $\left(<300^{\circ} \mathrm{C}\right)$. Kumar et al..$^{10}$ showed that sulphided $\mathrm{Co}-\mathrm{Mo} / \mathrm{Al}_{2} \mathrm{O}_{3}$ hydrotreating catalyst had an unusual cracking ability for jatropha oil with a high acid content. $\mathrm{Co}-\mathrm{Mo} / \mathrm{Al}_{2} \mathrm{O}_{3}$ despite being a low acidity catalyst gave an unexpectedly high yield (40\%) of cracked hydrocarbon products. Anand and Sinha have followed the reaction pathways for plant-oil hydroconversion over a CoMo system using a low free fatty acid feed to gain an understanding into the role of acidic intermediates in cracking. ${ }^{17}$ They reported formation of insoluble waxy oligomeric products at lower conversions. At lower temperature and higher space velocities $\left(320^{\circ} \mathrm{C}\right.$ and $\left.4 \mathrm{~h}^{-1}\right)$, concentration of oligomerized products was reported to be as high as 55\%. They grouped products with similar chemical functions as lumps and used them to model kinetic behaviour of the cracking process, and kinetic parameters and activation energy were evaluated. At higher space velocities of $17.5 \mathrm{~h}^{-1}$ and temperatures around $350^{\circ} \mathrm{C}$, Corma and coworkers $^{13}$ reported formation of insoluble white waxy high boiling fractions $\left(380^{\circ}\right.$ to $520^{\circ} \mathrm{C}$ fraction) product which accumulated in the reactor causing reactor plugging.

In this study, for further understanding of the reaction mechanisms, we study the formation of undesi- rable waxy intermediate, the process parameters influencing their formation and the possible reactions taking place over a Co- $\mathrm{Mo} / \mathrm{Al}_{2} \mathrm{O}_{3}$ catalyst for hydroprocessing of Jatropha curcus oil.

\section{Experimental}

Jatropha oil (1.7\% FFA (free fatty acids), having a composition of $19.5 \% \mathrm{C} 16: 0,7.9 \% \mathrm{C} 18: 0,45.4 \%$ $\mathrm{C} 18: 1,27.3 \% \mathrm{C} 18: 2,77.01$ wt\% C, 13.6 wt\% H, $9.39 \mathrm{wt} \% \mathrm{O}, 4.0 \mathrm{ppm} \mathrm{S}$ ) was hydroprocessed in a fixed-bed reactor over a sulphided $\mathrm{Co}-\mathrm{Mo} / \mathrm{Al}_{2} \mathrm{O}_{3}$ catalyst. Catalysts $(2.5 \mathrm{ml})$ mixed with $\mathrm{SiC}(2.5 \mathrm{ml})$ to ensure sufficient catalyst-bed length and to improve the reaction-heat transfer, were loaded into a stainless steel tubular reactor $(1.3 \mathrm{~cm}$ I.D. and $30 \mathrm{~cm}$ in length) and the experiments were carried in a commercial bench-top micro-reactor (Autoclave Engineers' BTRS-Jr) with singlezonetubular furnace, for vapour phase catalyst evaluation in continuous downflow mode. Hydrogen pressure was controlled by a back pressure regulator (Tescom), gas flow was controlled by a mass flow controller (Brooks), catalyst bed and temperatures were controlled and registered by temperature controllers and by two thermocouples. A liquid metering pump, high pressure (Eldex make) was used to maintain desired liquid flow. Liquid products were withdrawn after stabilization of reaction conditions in two-hour intervals (at each temperature) and were analysed using gas chromatography (GC: Make Varian 3800-GC-FID) to determine the activity of the catalyst. The liquid products were analysed offline after separation of the water phase A vf$5 \mathrm{~ms}$ column $(30 \mathrm{~m} \times 0.25 \mathrm{~mm}, 0.25 \mu \mathrm{m})$ was used for the analysis and internal standards (i.e., eicosane) were used for quantification. The results for the triglycerides were also cross checked with those from HPLC analysis after derivatization. The yield fractions were calculated on a relative basis and conversion defined as $\left(C_{\text {tgf }}-C_{\text {tgp }}\right) / C_{\text {tgf }} * 100$ where $\mathrm{C}_{\text {tgf }}$ and $\mathrm{C}_{\text {tgp }}$ are the concentrations of triglycerides in feed and reaction product.

The feed for the reaction was mixed with $0.1 \%$ DMDS (dimethyl disulphide) for maintaining catalytic activity. The triglycerides in the feed were taken as one lump and the products were lumped as heavy (from C15-C18) and oligomerized (>C18).

\section{Result and discussion}

Anomalous cracking of jathropha oil triglycerides in the presence of sulphided $\mathrm{Co}-\mathrm{Mo} / \mathrm{Al}_{2} \mathrm{O}_{3}$ catalyst $^{17}$ was 
studied by monitoring reaction intermediates produced at various processing conditions. Their formation and effects of various process parameters over these undesired products were understood through response surface studies. Figure 1 details the mean yield fraction of stable undesired waxy intermediate products formed during hydroconversion of triglycerides. Concentration of these stable undesired intermediates decreases with increase in residence time and reaction temperatures. At lower temperatures, i.e., $320^{\circ} \mathrm{C}$ and higher space velocities of $8 \mathrm{~h}^{-1}$, these undesired waxy products formed are very less $(4 \%)$; on decreasing the space velocity to $4 \mathrm{~h}^{-1}$ the concentration of these products doubles to $8 \%$ (figure 1 and supplementary figure 1) because of increased conversion of triglycerides into these waxy products. On increasing reaction temperature to $360^{\circ} \mathrm{C}$, similar concentrations of these waxy products was observed between 8 and $4 \mathrm{~h}^{-1}$ which further reduced at lower space velocities $\left(1-4 \mathrm{~h}^{-1}\right)$ as seen in chromatograms arranged in figure 2. Stable oxygenated intermediate products such as esters and some acids, alcohols, aldehydes and ethers were also confirmed by IR and NMR analyses by Anand and Sinha. ${ }^{17}$ Kubicka et al. ${ }^{15}$ observed large quantities of these intermediate oligomeric oxygenates (selectivity as high as $50 \%$ ) below $280^{\circ} \mathrm{C}$. Huber et al. ${ }^{13}$ explained the formation of these oxygenated intermediates prior to deoxygenation via the pathway $\mathrm{TG} \rightarrow$ hydrogenation $\rightarrow$ intermediates (waxes, glycerides, fatty acids, esters) $\rightarrow$ hydrocarbons. These indicate that triglycerides are converted to waxy products at reduced residence time, but on increasing residence time, their formation decreases. These white-coloured waxy products are formed due to $\mathrm{C}-\mathrm{C}$ coupling reactions such as aldol condensation, ketonization. The long chain organic acids, formed after depropanation reactions, first undergo decarboxylative coupling reactions to form ketones and alcohols which

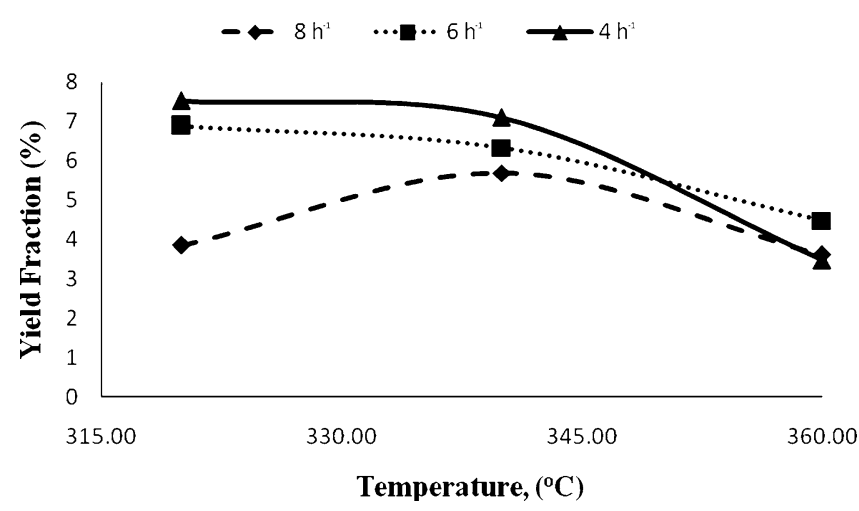

Figure 1. Mean yield fraction of stable undesired waxy products as a function of temperature $(80 \mathrm{bar}, 1500 \mathrm{vol} / \mathrm{vol})$.
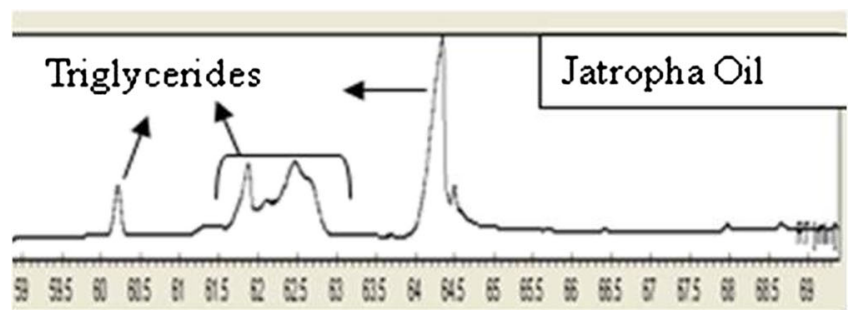

Undesired Waxy Pdt, P1

$360^{\circ} \mathrm{C}, 8 \mathrm{~h}^{-1}$

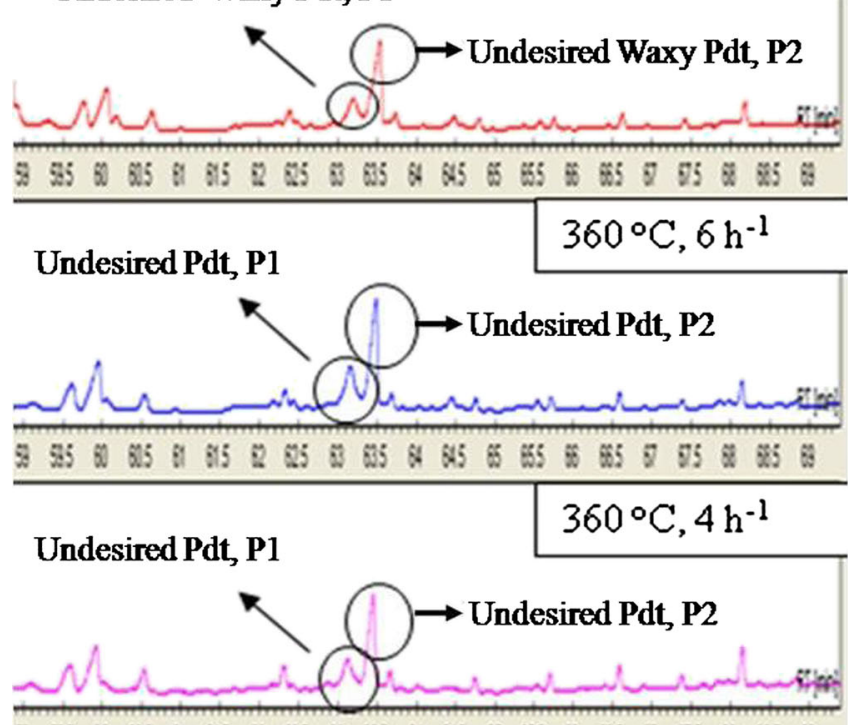

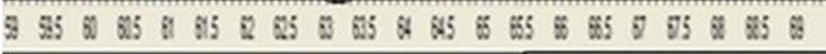

$360^{\circ} \mathrm{C}, 2 \mathrm{~h}^{-1}$

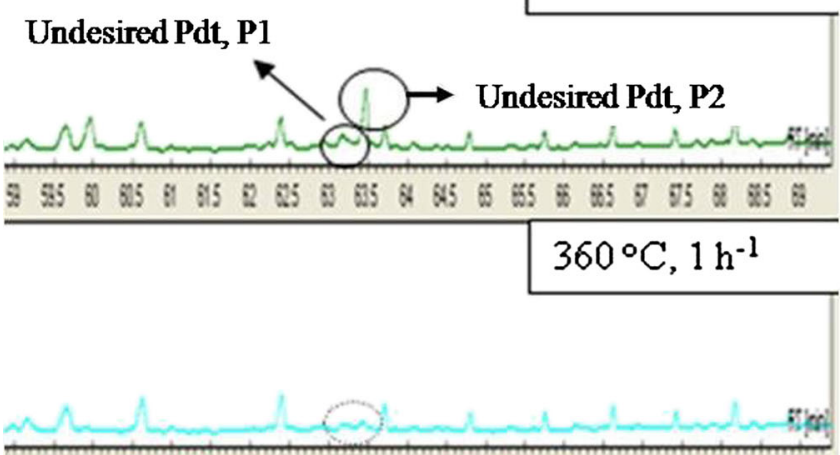

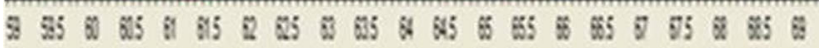

Figure 2. Gas chromatograms' for triglycerides and stable undesired waxy product concentration, observed at varying space velocities ( $80 \mathrm{bar}, 1500 \mathrm{vol} / \mathrm{vol}$ ) over $\mathrm{Co}-\mathrm{Mo} / \mathrm{Al}_{2} \mathrm{O}_{3}$ catalyst.

further react with aldehydes formed in the reaction media using the aldol condensation, leading to long chain waxy compounds. These reactions are undesirable in hydroconversion of triglycerides, as the products formed block the reaction sites and also act as sites for coke formation on the surface of the catalyst.

Our earlier studies ${ }^{8,17}$ discussed various temperaturedependent reaction pathways for processing of Jatropha 
curcus oil over Co-Mo catalytic system. After considering the product and conversion patterns, compound groups were divided into five different lumps. Here, we report the various response surfaces for depicting the multivariable effect over these different lumps and predict the optimum desired conditions for obtaining the desired product yield, complete conversions and minimum yield of undesired waxy products. Only those response surface models which satisfy the goodness of fit acceptance criteria to $95 \%$ confidence level are plotted and discussed below.

\subsection{Hydrogen to feed ratio and space velocity}

Different response surface graphs with the conversion of jatropha oil and yield fraction of various lumps as the response variable and hydrogen to feed ratio and space velocity as factors affecting the response variable were drawn. Figure 3 depicts the combined effect of hydrogen to feed ratio and space velocity over the conversion of triglyceride molecules. Contours for the parabolic model were slightly inclined to the horizontal, indicating a strong interaction of these variables to predict conversion of jatropha oil. The effect (figure 4) of these factors over oligomerized undesired product yield clearly shows an increase in the yield of these waxy products at higher space velocity and lower $\mathrm{H}_{2} / \mathrm{FEED}$ ratio, which was observed due to lower conversions. There was almost no interaction of space velocity and $\mathrm{H}_{2} /$ FEED at higher $\mathrm{H}_{2} /$ FEED ratios, but there was a slight effect of these factors on the response at lower $\mathrm{H}_{2} /$ FEED ratio. Combined interaction of space velocity and $\mathrm{H}_{2} /$ FEED ratio over the desired products, i.e.,

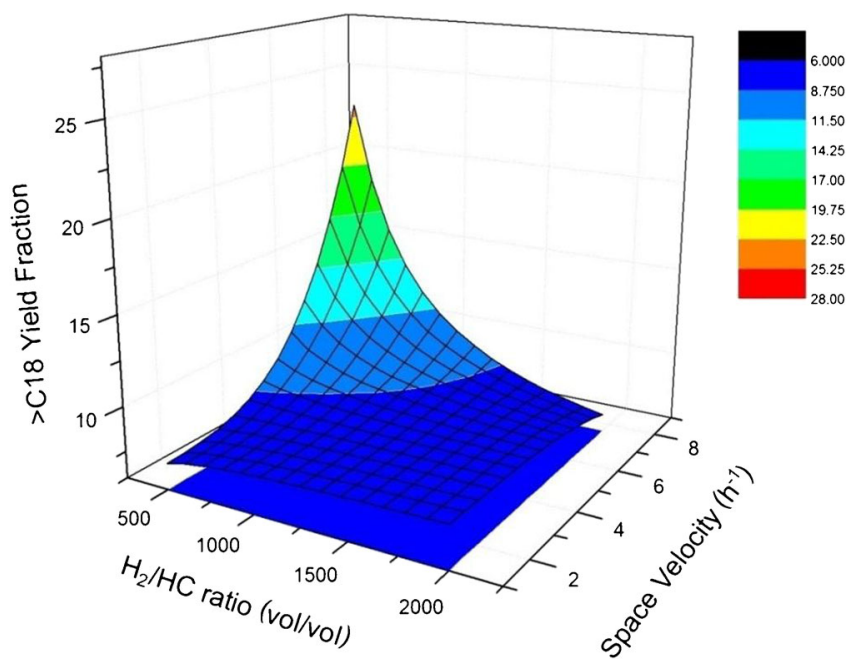

Figure 4. Yield fraction of undesired waxy product as a function of hydrogen to feed ratio and space velocity $\left(360^{\circ} \mathrm{C}\right.$, 80 bar) over $\mathrm{Co}-\mathrm{Mo} / \mathrm{Al}_{2} \mathrm{O}_{3}$ catalyst.

the heavy lump (C15-C18) is depicted in figure 5. The surface plot clearly shows $2-6 \mathrm{~h}^{-1}$ and 1500 as optimum space velocity and $\mathrm{H}_{2} / \mathrm{FEED}$ for maximizing its yield fraction, this is very well-supported by the fact that at higher space velocity, there is reduced conversion because of reduced residence time; and at lower space, velocities cracking of the heavier lump took place over Co-Mo catalyst. At higher $\mathrm{H}_{2} /$ FEED ratios, there was increased yield of C15-C18 product and lower yield was observed at reduced $\mathrm{H}_{2} / \mathrm{FEED}$ ratios which is very much in accordance to conversion of triglycerides and formation of unwanted waxy products. The two

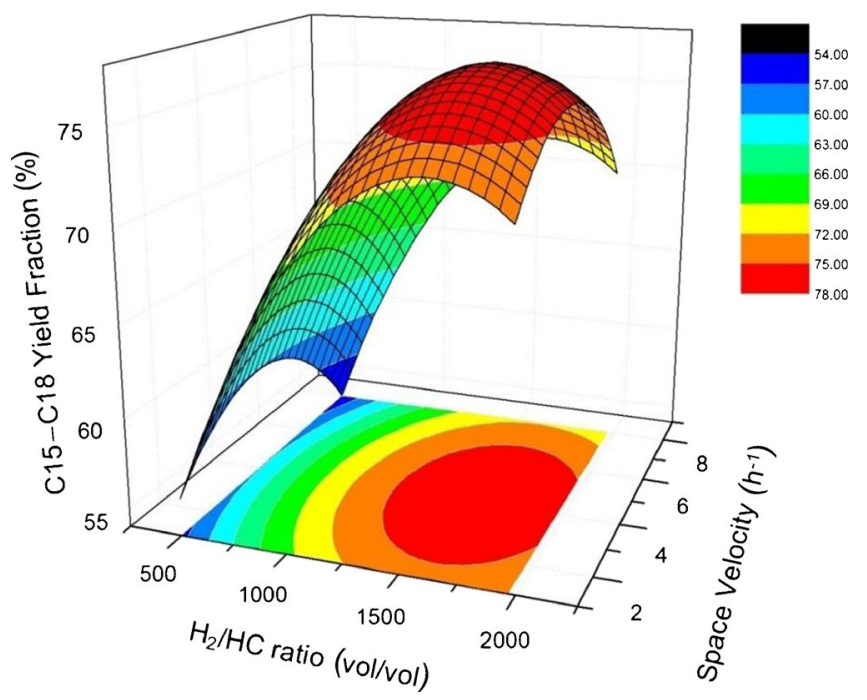

Figure 5. Yield fraction of C15-C18 lump as a function of hydrogen to feed ratio $\left(\mathrm{H}_{2} / \mathrm{FEED}\right)$ and space velocity $\left(360^{\circ} \mathrm{C}, 80 \mathrm{bar}\right)$ over $\mathrm{Co}-\mathrm{Mo} / \mathrm{Al}_{2} \mathrm{O}_{3}$ catalyst.
Figure 3. Conversion of triglycerides as a function of hydrogen to feed ratio and space velocity $\left(360^{\circ} \mathrm{C}, 80\right.$ bar) over $\mathrm{Co}-\mathrm{Mo} / \mathrm{Al}_{2} \mathrm{O}_{3}$ catalyst.
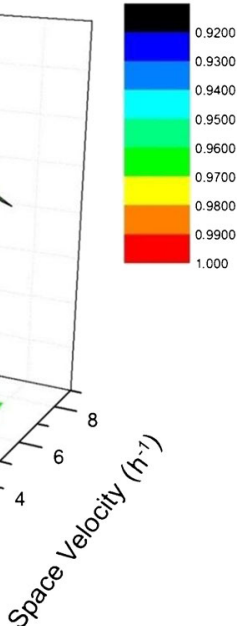


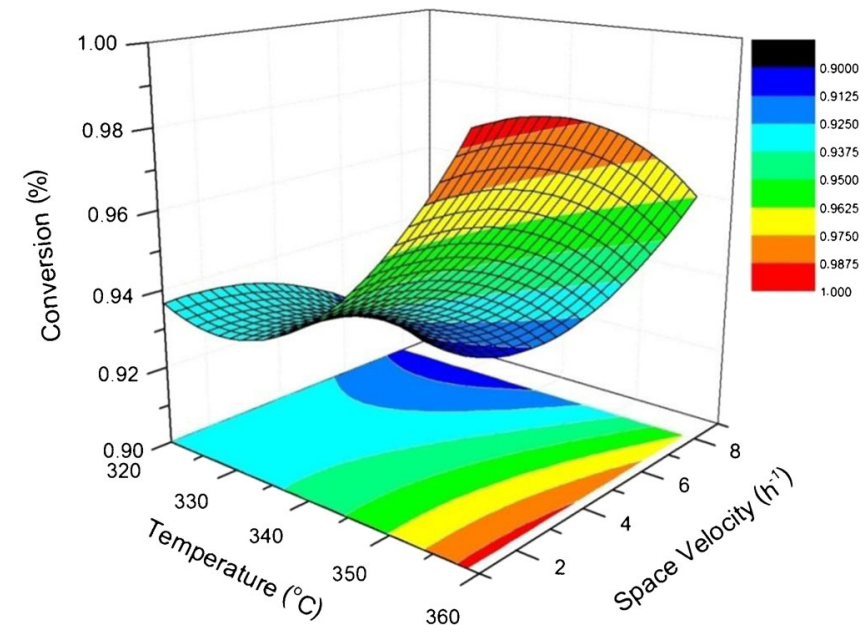

Figure 6. Conversion of triglycerides as a function of temperature and space velocity (1500 vol/vol, 80 bar) over $\mathrm{Co}-\mathrm{Mo} / \mathrm{Al}_{2} \mathrm{O}_{3}$ catalyst.

parameters for the response of heavy lump yield fraction interact only at extreme conditions (figure 5).

\subsection{Temperature and space velocity}

Response surface which depicts the combined variation for conversion of jatropha oil, with respect to temperature and space velocity is plotted in figure 6 . The parabolic model satisfies the statistical criteria and has a very high $F$ value indicating a very strong interaction between temperature and space velocity for predicting the response and conversion.

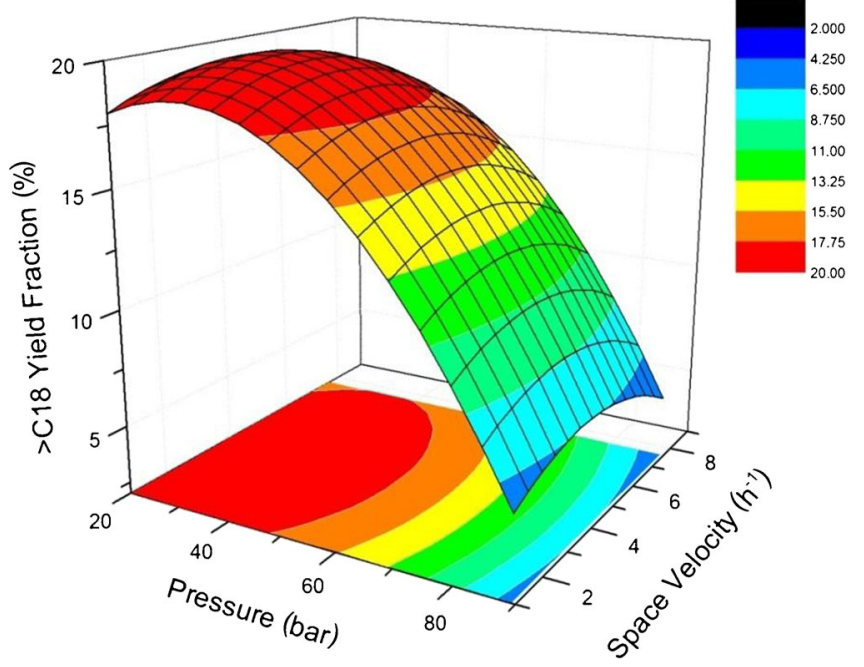

Figure 8. Yield fraction of oligomerized (>C18) lump as a function of pressure and space velocity $\left(1500 \mathrm{vol} / \mathrm{vol}, 360^{\circ} \mathrm{C}\right)$ over $\mathrm{Co}-\mathrm{Mo} / \mathrm{Al}_{2} \mathrm{O}_{3}$ catalyst.

98.9\% conversion was achieved at higher severities, i.e. $360^{\circ} \mathrm{C}$ temperature and $2 \mathrm{~h}^{-1}$ space velocities. At lower severities, i.e., $320^{\circ} \mathrm{C}$, conversion of triglycerides varied between 90 and $94 \%$ at different space velocities but with increased formation of oxygenated waxy products. With increase in temperature to $360^{\circ} \mathrm{C}$, conversion increased further with increased conversion of these waxy intermediated into hydrocarbons (figures 1 and 6). At higher temperatures $\left(360^{\circ} \mathrm{C}\right)$ the contours observed were parallel to the space velocity axis at lower space velocities $\left(1-4 \mathrm{~h}^{-1}\right)$ and then slightly inclined at higher space

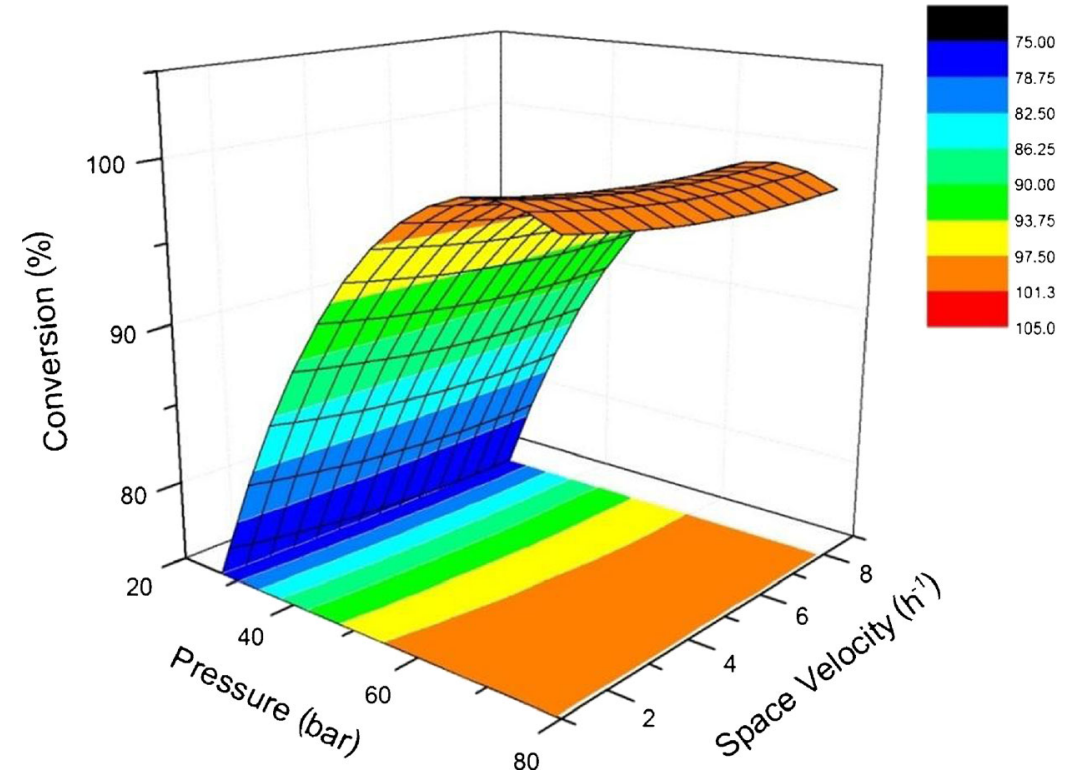

Figure 7. Conversion of triglycerides as a function of pressure and space velocity $\left(360^{\circ} \mathrm{C}, 1500 \mathrm{vol} / \mathrm{vol}\right)$ over $\mathrm{Co}-\mathrm{Mo} / \mathrm{Al}_{2} \mathrm{O}_{3}$ catalyst. 
velocities $\left(4-8 \mathrm{~h}^{-1}\right)$ indicating reduced dependence of space velocities at higher temperatures for predicting conversions of triglyceride molecule. The results also concur to the temperature-dependent pathways predicted by Anand and $\mathrm{Sinha}^{17}$ for the conversion of jatropha oil over $\mathrm{Co}-\mathrm{Mo} / \mathrm{Al}_{2} \mathrm{O}_{3}$ catalytic system.

\subsection{Pressure and space velocity}

Figure 7 details the combined interaction of pressure and space velocity over the conversion. The contours clearly depict no interactions between the factors, with reduced conversions obtained at lower pressures below 40 bar, and almost constant conversions above 55 bars. In the studied range of pressures (25-80 bar), the contours observed were parallel to the space velocity axis at $360^{\circ} \mathrm{C}$, indicating enough partial pressures of hydrogen were available at all velocities $\left(1-8 \mathrm{~h}^{-1}\right)$ required for conversion of triglyceride molecule. The oligomerized product increases (figure 8) at lower pressures because of increased $\mathrm{C}-\mathrm{C}$ coupling reactions favoured at lower partial pressures of hydrogen. At higher pressure ( $>55$ bar), the yield of unwanted waxy product was almost constant at different space velocities at $360^{\circ} \mathrm{C}$ and $1500 \mathrm{Nl} / \mathrm{l} \mathrm{H}_{2} / \mathrm{FEED}$ ratio. At lower pressure ( $<50 \mathrm{bar})$, the contours are inclined at higher space velocities (lower residence time and hence reduced conversions) and at lower space velocities (higher residence time and hence increased conversions); indicating a combined interaction effect of space velocity and hydrogen partial pressure over the formation of these oligomerized products at these pressures.

Mechanisms for the hydroprocessing of jatropha oil triglycerides are likely to be complex due to multiplicity

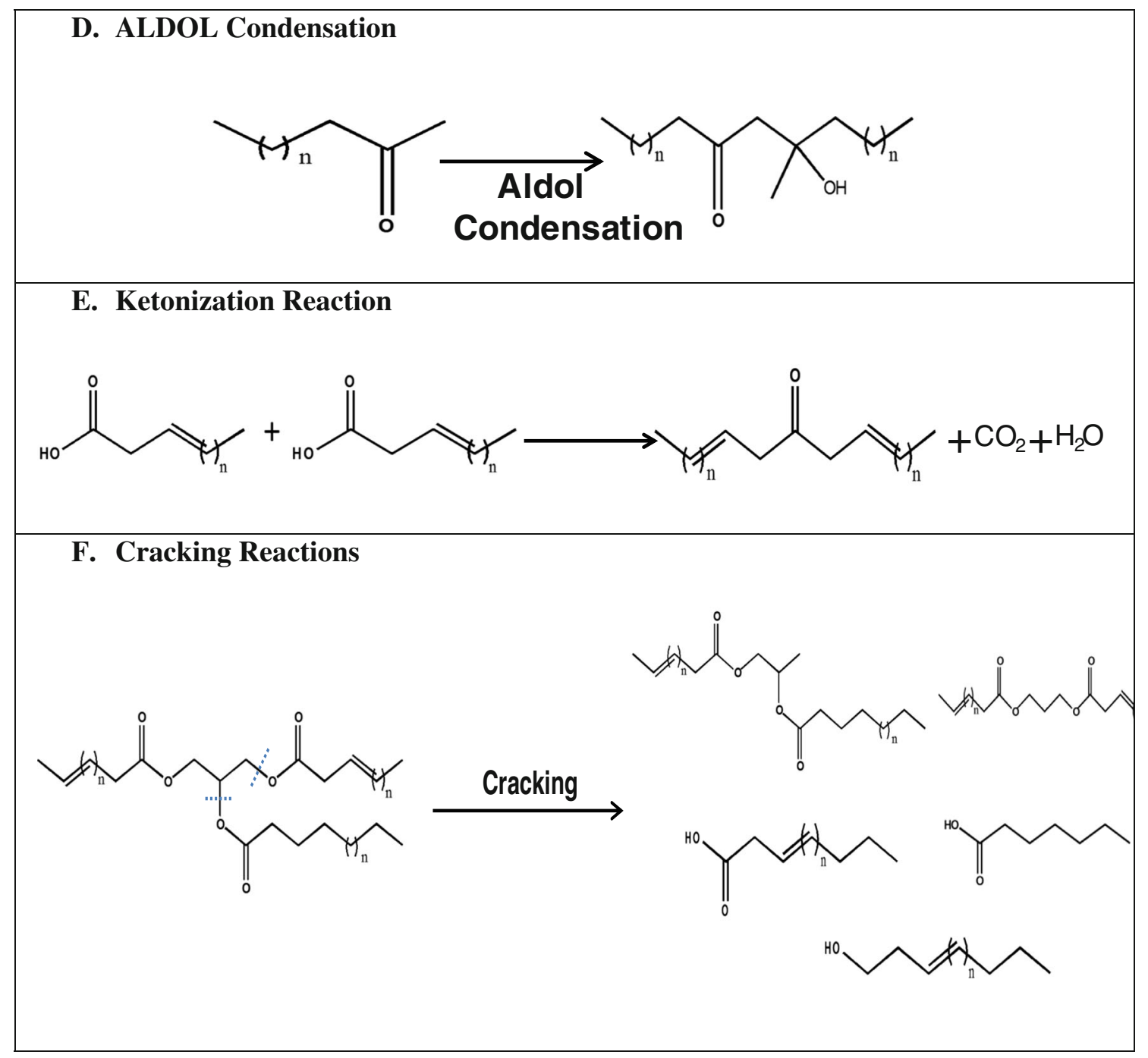

Scheme 1. Reaction mechanics for formation of unwanted waxy intermediates through $\mathrm{C}-\mathrm{C}$ coupling reactions over $\mathrm{Co}-\mathrm{Mo} / \mathrm{Al}_{2} \mathrm{O}_{3}$ catalyst. 


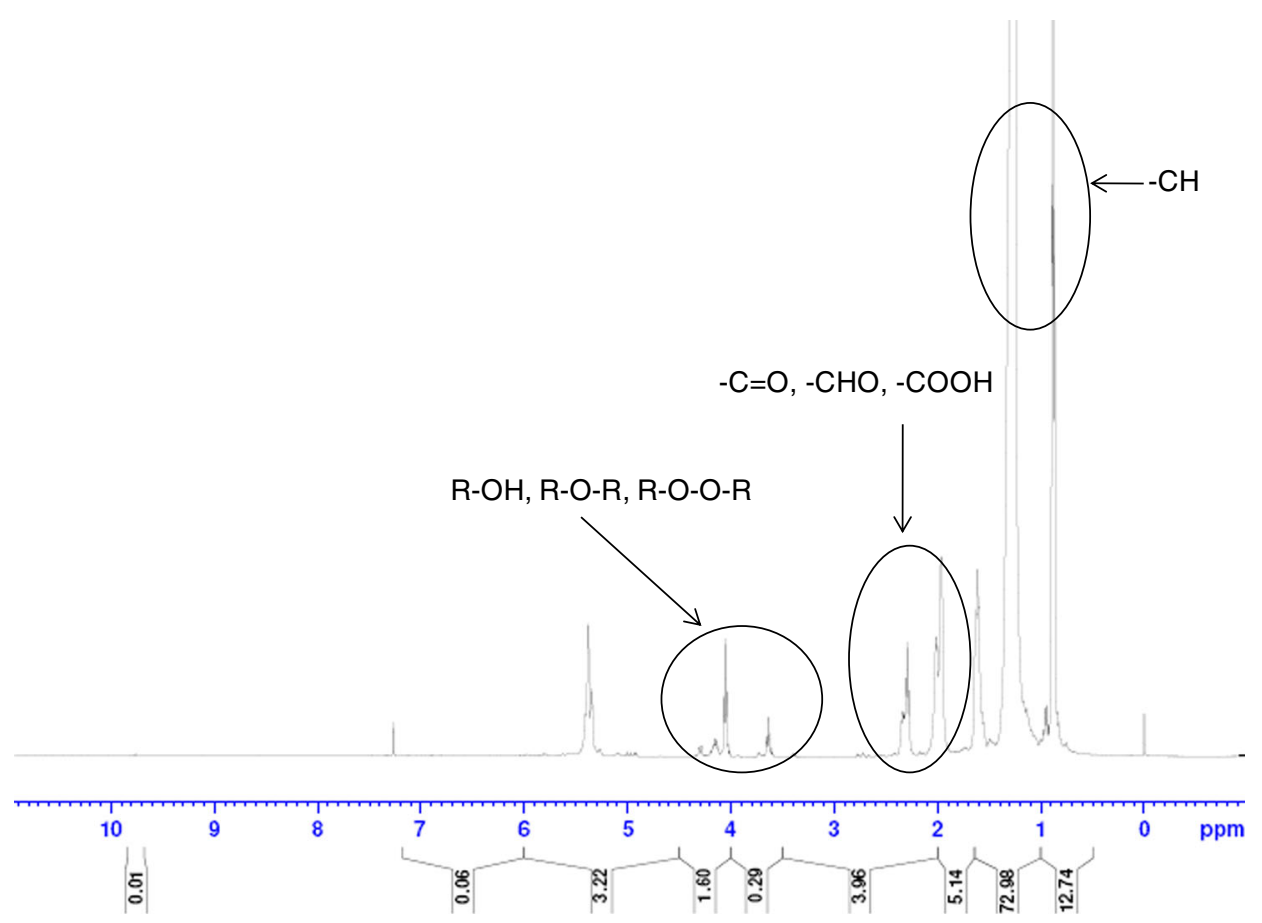

Figure 9. 1H NMR spectrum for the oligomeric intermediate compounds at $340^{\circ} \mathrm{C}, 80 \mathrm{bar}, 1500 \mathrm{NL} / \mathrm{L}$.

of the possible reactions of mixed triglycerides. Generally, formation of hydrocarbons proceeds through the decomposition and cleavage of the bonds and disproponation reactions. Presence of unsaturation enhances cleavage at a position $\alpha, \beta$ to the unsaturation. It is generally known that triglycerides are first saturated on their side chain and followed by cleavage of the $\mathrm{C}-\mathrm{O}$ bond leading to formation of monoglycerides, diglycerides, carboxylic acids and waxes. Presence of unsaturation also leads to unwanted $\mathrm{C}-\mathrm{C}$ coupling reactions which produces stable unconverted intermediates. The main reaction pathways leading to formation of these intermediates are shown in scheme 1. Oligomerization, aldol condensation, ketonization, etc. are the main reactions for the formation of these intermediates (figure 2). Presence of oxygenated species indicated by the $\mathrm{C}=\mathrm{O}$ band and $\mathrm{OH}$ stretchings observed at $340^{\circ} \mathrm{C}$ temperature ${ }^{17}$ indicated presence of acidic intermediates which was also justified by increased total acid number at these conditions. To confirm the presence of these intermediates, ${ }^{1} \mathrm{H}-\mathrm{NMR}$ analysis was carried out (figure 9). Chemical shifts were observed between 0.7 and $2 \mathrm{ppm}$ for the $\mathrm{sp}^{3}$ hybridized $-\mathrm{CH}$ with no functional group attached, indicating the presence of paraffinic carbon. Chemical shifts observed between 2.8 and $4.5 \mathrm{ppm}$ indicate the presence of oxygenated $\mathrm{sp}^{3}$ hybridized $\mathrm{C}-\mathrm{H}$ present in alcohols, ethers and esters. Chemical shifts for allylic sp3 hybridized $\mathrm{C}-\mathrm{H}$ for ketones $(\mathrm{C}=\mathrm{O})$, aldehydes $(-\mathrm{CHO})$, and acids $(-\mathrm{COOH})$ were also observed between 1.8 and $2.8 \mathrm{ppm}$ in the ${ }^{1} \mathrm{H}$ NMR spectra, confirming and justifying the increased TAN and hence the $\mathrm{C}-\mathrm{C}$ coupling reactions which produce these waxy intermediates.

\section{Conclusion}

Formation of unwanted waxy products could be minimized by minimizing the $\mathrm{C}-\mathrm{C}$ coupling reactions taking place at reduced partial pressures of hydrogen and reduced conversions. Higher partial pressures could be achieved by either increasing the reactor pressure (60 bar or more) or by increasing the $\mathrm{H}_{2}$ /FEED ratio $(1500 \mathrm{Nl} / \mathrm{l}$ or more). Lower pressures and lower H2/FEED ratio promotes their formation by favouring aldol condensation and ketonization reactions. As lower conversions were achieved at lower temperatures and higher space velocities; hence, higher temperatures $\left(360^{\circ} \mathrm{C}\right.$ or more) and lower space velocities $\left(2 \mathrm{~h}^{-1}\right.$ or less) were necessary for minimizing the formation of these waxy intermediates. Minimizing these intermediate reactions would enhance catalyst life and also increase selectivity of the desired reaction productive by reducing competitive reactions.

\section{Supplementary information}

The electronic supporting information can be seen at www.ias.ac.in/chemsci. 


\section{Acknowledgements}

MGS and DV thank the University Grants Commission (UGC) New Delhi, India for fellowship.

\section{References}

1. Alvarez A and Ancheyta J 2008 Appl. Catal., A: Gen. 351148

2. Bezergianni S, Kalogianni A and Vasalos I A 2009 Bioresour. Technol 1003036

3. Bezergianni S, Voutetakis S and Kalogianni A 2009 Ind. Eng. Chem. Res. 488402

4. Callejas M A and Martinez M T 2000 Energy Fuels 14 1309

5. Donnis B, Egeberg R G, Blom P and Knudsen K G 2009 Top. Catal. $\mathbf{5 2} 229$

6. Dupont J, Suarez P A Z, Meneghetti M R and Meneghetti S M P 2009 Energy Environ. Sci. 21258

7. Taufiqurrahmi N and Bhatia S 2011 Energy Environ. Sci. 41087
8. Sinha A K, Anand M, Rana B S, Kumar R, Farooqui S A, Sibi M G, Kumar R and Joshi R K 2013 Catal. Surv. Asia 171

9. Kumar H and Froment G F 2007 Ind. Eng. Chem. Res. 465881

10. Kumar R, Rana B S, Tiwari R, Verma D, Kumar R, Joshi R K, Garg M O and Sinha A K 2010 Green Chem. 12 2232

11. Tiwari R, Rana B S, Kumar R, Verma D, Kumar R, Joshi R K, Garg M O and Sinha A K 2011 Catal. Commun. 12559

12. Verma D, Kumar R, Rana B S and Sinha A K 2011 Energy Environ. Sci. 41667

13. Huber G W, Connor P O and Corma A 2007 Appl. Catal., A: Gen. 329120

14. Kubickova I and Kubička D 2010 Waste Biomass Valor. 1293

15. Kubicka D, Simacek P and Zilkova N 2009 Top. Catal. 52161

16. Krár M, Kovács S, Kalló D and Hancsók J 2010 Bioresour. Technol. 1019287

17. Anand M and Sinha A K 2012 Bioresour. Technol. 126 148 